Jurnal Kebidanan dan Keperawatan 'Aisyiyah, 17 (1), 2021, 111-119

\title{
Hubungan Faktor Risiko Dengan Prediktor Preventif Diabetes Mellitus Pada Remaja
}

\author{
Indah Puspitasari ${ }^{1}$, Muftadi ${ }^{2}$, Meria Woro $\mathbf{L}^{3^{*}}$ \\ 1,2,3 Sekolah Tinggi Ilmu Kesehatan Bani saleh, J1.RA Kartini No.66,Kota Bekasi 17113, Indonesia \\ indahpuspitasari.ners@gmail.com; adimuftadi86@gmail.com; spkepkom@gmail.com \\ * corresponding author \\ Tanggal Submisi: 20 Februari 2021, Tanggal Diterima: 8 Maret 2021
}

\begin{abstract}
Abstrak
Penelitian ini bertujuan untuk mengidentifikasi hubungan faktor risiko dengan prediktor faktor preventif diabetes mellitus pada remaja yakni pengetahuan tentang diabetes, pola makan dan pola olahraga. Desain penelitian ini menggunakan metode kuantitatif dengan pendekatan cross-sectional. Populasi pada penelitian ini adalah remaja usia 15-18 tahun yang duduk di bangku SMA dengan jumlah sampel 162 remaja. Pemilihan sampel penelitian dilakukan dengan teknik incidental sampling. Data penelitian diambil dengan cara membagikan kuesioner faktor risiko dan faktor prediktor preventif. Hasil penelitian menunjukan terdapat hubungan antara faktor risiko dengan faktor prediktor faktor preventif diabetes mellitus pada remaja. Penelitian selanjutnya diharapkan dapat melihat efektifitas edukasi terhadap pencegahan dini terjadinya diabetes mellitus pada remaja.
\end{abstract}

Kata kunci: remaja, diabetes mellitus, preventif, faktor risiko

\section{Correlation of Risk Factors with Preventive Predictors of Diabetes Mellitus in Adolescents}

\begin{abstract}
The purpose of this study was to identify the relationship between risk factors and predictors of diabetes mellitus preventive factors in adolescents, namely knowledge of diabetes, diet and exercise patterns. This research design uses quantitative methods with cross sectional approach. The population in this study were adolescents aged 15-18 years who were in high school with a sample of 162 adolescents. The selection of the research sample was carried out by using the incidental sampling technique. The research data were collected by distributing questionnaires about risk factors and preventive predictor factors. The results showed that there was a relationship between risk factors and predictor factors for preventing diabetes mellitus in adolescents. It is hoped that further research can see the effectiveness of education on early prevention of diabetes mellitus in adolescents.
\end{abstract}

Keywords: adolescents, diabetes mellitus, preventive, risk factors 


\section{PENDAHULUAN}

Riset Kesehatan Dasar (Riskesdas) tahun 2018 menyebutkan Penyakit Tidak Menular (PTM) dengan usia penderita $\geq 15$ tahun. Tercatat penderita diabetes mellitus mengalami peningkatan angka kejadian dan angka kematian hingga 1,5 juta kematian pada usia 20-69 tahun (Kemenkes RI, 2018). Maka dapat diartikan bahwa mulai dari usia 15 tahun remaja sudah ada remaja yang terdiagnosa PTM. Diabetes Mellitus adalah satu dari beberapa Penyakit Tidak Menular dengan angka kejadian yang semakin meningkat pada usia $\geq 15$ tahun sebesar 6,3\% tahun 2013 menjadi 8,5\% tahun 2018 (Riskesdas, 2018). Penelitian Qifti, Malini, \& Yetti (2020) menyebutkan bahwa sebanyak 48\% remaja usia 16 tahun dan $16,4 \%$ remaja usia 15 tahun memiliki faktor risiko diabetes mellitus.

Persentasi penduduk Indonesia yang memiliki faktor risiko terdiagnosa diabetes mellitus karena kegemukan atau berat badan berlebih pada usia 5-12 tahun mencapai 10,8\%, usia 13-15 mencapai 8,3\% dan 16-18 tahun 5,7\%. Faktor risiko lainnya seperti aktifitas fisik kurang aktif pada usia 10 tahun ke atas mencapai 26,1\% (BPS, 2016). Sedangkan faktor risiko yang menyebabkan diabetes mellitus paling banyak pada populasi 10 tahun ke atas adalah diet tidak seimbang seperti mengkonsumsi makanan atau minuman manis lebih dari satu kali $(35,9 \%)$, mengkonsumsi makanan atau minuman asin lebih dari satu kali per hari $(26,2 \%)$ serta mengkonsumsi makanan berlemak lebih dari satu kali perhari $(40,7 \%)$. Selain itu merokok juga menjadi faktor risiko dibetes mellitus pada usia 10 tahun ke atas $(24,3 \%)$ (BPS, 2016). Oleh karena itu, remaja menjadi salah satu fokus usia yang menjadi target pembangunan kesehatan pada pencegahan diabetes mellitus.

Sustainable Development Goals (SDGs) dalam tujuannya yang ketiga yakni memastikan kehidupan yang sehat dan mendukung kesejahteraan bagi semua usia. Salah satu target capaian pada tujuan ini adalah pada tahun 2030 mengurangi sepertiga dari kematian dini yang disebabkan oleh penyakit tidak menular, melalui tindakan pencegahan dan pengobatan serta menaikkan kesehatan mental dan kesejahteraan (Kemenkes, 2017). Upaya pencegahan lebih dini penyakit diabetes mellitus yaitu dengan cara mengidentifikasi status dan prediktor perilaku preventif gizi diabetes mellitus pada remaja.

Remaja dengan masa perkembangannya yang sedang mencari jati diri akan dengan mudah mengikuti perilaku teman sebayanya (Lee et al., 2017). Center for Dease Control and Prevention (CDC) tahun 2018 menyebutkan bahwa usia adalah salah satu faktor risiko dari terjadinya diabetes mellitus. Diabetes dapat terjadi pada remaja di pedesaan dengan faktor risiko perubahan gaya hidup. Umumnya usia 15-19 tahun remaja laki-laki telah memiliki gaya hidup yang menetap dibandingkan usia dibawahnya. Selain itu remaja perempuan lebih cenderung memiliki gaya hidup yang sudah menetap dibandingkan laki-laki (Gaidhane et al., 2017). Kegemukan menjadi salah satu penyebab yang dapat menjadi faktor risiko timbulnya diabetes pada remaja (Amiri et al., 2015). Penentuan faktor risiko diabetes mellitus pada remaja dapat dilakukan dengan skrining awal. Rerata skrining yang telah dilakukan menunjukan data yang hasil 
yang abnormal pada remaja yakni memiliki gejala prediabetes dan diabetes tipe 2 sebesar 5,4\% (Amiri et al., 2015). Peningkatan angka kejadian diabetes mellitus setiap tahunnya yang terjadi mulai dari usia remaja akan memicu tingginya penyakit komplikasi lainnya. Sehingga perlu adanya pemutusan rantai kejadian diabetes mellitus dengan mengidentifikasi hubungan faktor risiko dengan prediktor faktor preventif diabetes mellitus pada remaja.

\section{METODE}

Desain penelitian ini menggunakan metode kuantitatif dengan pendekatan cross-sectional. Populasi pada penelitian ini adalah remaja usia 15-18 tahun yang duduk di bangku SMA dengan jumlah sampel 162 remaja. Penentuan sampel dilakukan dengan cara multistage sampling untuk pemilihan tempat penelitian dikarenakan wilayah penelitian yang luas. Sedangkan pemilihan responden penelitian dilakukan dengan incidental sampling. Data penelitian diambil dengan cara membagikan kuesioner dengan nilai validitas $\alpha$ Cronbach $=0,686$. Kuesioner karakteristik umum yakni usia, jenis kelamin, uang jajan perhari, tinggi badan, berat badan dan riwayat diabetes mellitus pada keluarga. Kuesioner faktor prediktor preventif terdiri dari pengetahuan tentang DM (8 item), pola makan ( 9 item), dan pola olahraga (10 item).

Pengolahan data dilakukan melalui editing, coding dan tabulating yang dilanjutkan dengan analisa menggunakan uji multiple linear regression. $P$-value < 0,05 ditetapkan sebagai tingkat signifikansi statistik. Variabel dependen dari penelitian ini adalah faktor prediktor preventif (pengetahuan diabetes mellitus, pola makan dan olahraga), sedangkan variabel independen yakni faktor risiko (usia, jenis kelamin, IMT, riwayat keluarga diabetes mellitus).

\section{HASIL DAN PEMBAHASAN}

Hasil pada tabel 1 menunjukan bahwa usia responden paling banyak adalah usia 17 tahun $(38,5 \%)$ dengan jenis kelamin perempuan sebanyak 130 responden $(80,7 \%)$. Sebanyak 134 responden atau $(83,2 \%)$ menyatakan bahwa uang jajan perhari $\leq \mathrm{Rp} 20.000,00$. Responden dengan nilai IMT 18,5-22,9 paling banyak pada penelitian ini yaitu 60 siswa (37,3\%). Selain itu sebanyak 101 responden atau $62,7 \%$ menyatakan bahwa terdapat riwayat keluarga yang menderita diabetes mellitus.

Tabel 1. Distribusi frekuensi usia, jenis kelamin, uang jajan perhari, riwayat keluarga diabetes mellitus

\begin{tabular}{|c|c|c|c|}
\hline & \multirow{2}{*}{ Variabel } & \multicolumn{2}{|c|}{ responden (162) } \\
\hline & & $\mathrm{n}$ & $\%$ \\
\hline \multicolumn{4}{|c|}{ Usia (tahun) } \\
\hline 15 tahun & & 41 & 25,5 \\
\hline 16 tahun & & 26 & 16,1 \\
\hline 17 tahun & & 62 & 38,5 \\
\hline 18 tahun & & 32 & 19,9 \\
\hline
\end{tabular}

Indah Puspitasari, et.al (Hubungan Faktor Risiko Dengan Prediktor Preventif....) 


\begin{tabular}{lcc}
\hline Jenis Kelamin & 31 & 19,3 \\
Laki-laki & 130 & 80,7 \\
Perempuan & & \\
\hline Uang jajan perhari (rupiah) & 134 & 83,2 \\
$\leq 20.000$ & 25 & 15,5 \\
$20.000-50.000$ & 2 & 1,2 \\
$\geq 50.000$ & & \\
\hline IMT $\left(\mathrm{kg} / \mathrm{m}^{2}\right)$ & 52 & 32,3 \\
$<18,5$ & 60 & 37,3 \\
$18,5-22,9$ & 24 & 14,9 \\
$23-24,9$ & 20 & 12,4 \\
$25-29,9$ & 5 & 3,1 \\
$>30$ & & \\
\hline Riwayat Keluarga diabetes Mellitus & 101 & 62,7 \\
Ada & 60 & 37,3 \\
Tidak & & \\
\hline
\end{tabular}

Sumber: data primer

Hasil uji korelasi pada tabel 2 menunjukan bahwa $p$-value $=0,042<0,05$ maka dapat disimpulkan bahwa terdapat hubungan antara faktor risiko (usia, jenis kelamin, IMT dan riwayat keluarga diabetes mellitus) dengan prediktor preventif diabetes mellitus (pengetahuan diabetes mellitus). Besarnya nilai korelasi atau hubungan ditunjukan dengan nilai $\mathrm{R}$. Hal ini berarti nilai hubungan antara faktor risiko (usia, jenis kelamin, IMT dan riwayat keluarga diabetes mellitus) dengan prediktor faktor preventif diabetes mellitus (pengetahuan diabetes mellitus) sebesar 0,283. Selain itu dapat dilihat juga bahwa koefisien determinan $\left(\mathrm{R}^{2}\right)$ sebesar 0,080 . Sehingga disimpulkan pengaruh faktor risiko (usia, jenis kelamin, IMT dan riwayat keluarga diabetes mellitus) terhadap prediktor faktor preventif diabetes mellitus (pengetahuan diabetes mellitus) sebesar $8 \%$, sedang sisanya $92 \%$ dipengaruhi oleh faktor lain.

Tabel 2. hubungan faktor risiko dengan prediktor faktor preventif diabetes mellitus pada remaja

\begin{tabular}{lccc}
\hline \multicolumn{1}{c}{ Variable Independent } & \multicolumn{3}{c}{ Variabel Dependen } \\
\cline { 2 - 4 } & $R$ & Pengetahuan diabetes mellitus \\
& & & r-square \\
Usia & 0,283 & 0,080 \\
Jenis kelamin & & & 0,042 \\
IMT & & \\
Riwayat keluarga diabetes mellitus & & \\
\hline Sumber: data primer & &
\end{tabular}

Hasil pada tabel 3 menunjukkan $p$-value $=0,040<0,05$ maka dapat disimpulkan terdapat hubungan antara faktor risiko (usia, jenis kelamin, IMT dan riwayat keluarga diabetes mellitus) dengan prediktor preventif diabetes mellitus (pola makan). Besarnya hubungan antara faktor risiko (usia, jenis kelamin, IMT dan riwayat keluarga diabetes mellitus) dengan prediktor faktor preventif diabetes mellitus (pola makan) sebesar 0,268. Sedangkan pengaruh faktor risiko (usia, jenis kelamin, IMT dan riwayat keluarga diabetes mellitus) terhadap prediktor faktor 
preventif diabetes mellitus (pola makan) sebesar $7,2 \%$, sedang sisanya $83,8 \%$ dipengaruhi oleh faktor-faktor lain.

Tabel 3. hubungan faktor risiko dengan prediktor faktor preventif diabetes mellitus pada remaja

\begin{tabular}{lccc}
\hline \multicolumn{1}{c}{ Variable Independent } & \multicolumn{3}{c}{ Variabel Dependen } \\
\cline { 2 - 3 } & $R$ & Pola makan \\
& & r-square & p-value \\
\hline Usia & 0,268 & 0,072 & 0,040 \\
Jenis kelamin & & & \\
IMT & & \\
Riwayat keluarga diabetes mellitus & &
\end{tabular}

Hasil pada tabel 4 menunjukan nilai $p$-value $=0,003<0,05$ maka dapat disimpulkan terdapat hubungan antara faktor risiko (usia, jenis kelamin, IMT dan riwayat keluarga diabetes mellitus) dengan prediktor preventif diabetes mellitus (pola olahraga). Besar nilai hubungan antara faktor risiko (usia, jenis kelamin, IMT dan riwayat keluarga diabetes mellitus) dengan prediktor faktor preventif diabetes mellitus (pola olahraga) sebesar 0,342. Sedangkan pengaruh faktor risiko (usia, jenis kelamin, IMT dan riwayat keluarga diabetes mellitus) terhadap prediktor faktor preventif diabetes mellitus (pola olahraga) sebesar $11,7 \%$, sedang sisanya $89,3 \%$ dipengaruhi oleh faktor-faktor lain.

Table 4. hubungan faktor risiko dengan prediktor faktor preventif diabetes mellitus pada remaja

\begin{tabular}{lccc}
\hline \multicolumn{1}{c}{ Variable Independent } & \multicolumn{3}{c}{ Variabel Dependen } \\
\cline { 2 - 3 } & $R$ & Pola olahraga \\
r-square & p-value \\
\hline Usia & & & \\
Jenis kelamin & 0,342 & 0,117 & 0,003 \\
IMT & & & \\
Riwayat keluarga diabetes mellitus & & \\
\hline
\end{tabular}

Sumber: data primer

Remaja digolongkan menjadi tiga periode yaitu remaja awal (10-14 tahun), masa remaja pertengahan (14-17 tahun) dan masa remaja akhir (17-19 tahun) (Kozier \& Snyder, 2011). Usia remaja yang ditunjukan pada tabel 1 paling banyak adalah usia 17 tahun sebanyak 62 responden. Sejalan dengan penelitian Widodo \& Retnaningtyas (2012) yang melakukan penelitian faktor risiko timbulnya kejadian diabetes mellitus pada remaja dengan responden paling banyak remaja usia 16 tahun. Hal ini menunjukan usia remaja menjadi salah satu faktor risiko pada diabetes mellitus. Smeltzer \& Bare (2013) menyebutkan bahwa faktor-faktor risiko diabetes mellitus adalah riwayat keluarga, usia, kelompok etnis dan berat badan. Usia remaja merupakan usia yang tepat untuk melakukan pencegahan tingkat dasar usia, jenis kelamin dan keturunan merupakan faktor risiko yang 
tidak dapat diperbaharui, sedangkan pengetahuan, pola makan, hipertensi dan aktivitas fisik adalah faktor yang dapat diperbaharui (Bustan, 2014).

Jenis kelamin juga dapat menjadi faktor risiko terjadinya diabetes mellitus pada remaja. Diketahui pada tabel 1 bahwa responden dengan jenis kelamin perempuan jumlahnya paling banyak $(80,7 \%)$. Sejalan dengan penelitian Silalahi, (2019) yang mendapatkan responden perempuan sebesar $59 \%$ pada penelitian hubungan pengetahuan dengan tindakan pencegahan DM remaja. Perempuan lebih berisiko mengidap diabetes karena secara fisik perempuan memiliki peluang peningkatan indeks masa tubuh yang lebih besar. Sindroma siklus bulanan (premenstrual syndrome), pasca-menopouse yang membuat distribusi lemak tubuh menjadi mudah terakumulasi akibat proses hormonal tersebut sehingga perempuan berisiko menderita diabetes mellitus tipe 2 (Wahyuni \& Alkaff, 2013).

Responden remaja pada penelitian ini menunjukan sebagian besar 37,3\% berada pada rentang $18,5-22,9 \mathrm{~kg} / \mathrm{m} 2$. Angka ini menunjukan status normal namun perlu diwaspadai karena sebesar $12,4 \%$ remaja berada pada rentan $25-29,9$ $\mathrm{kg} / \mathrm{m} 2$ menunjukan berat badan berlebih dan $3,1 \%$ berada pada rentang $>30$ $\mathrm{kg} / \mathrm{m} 2$ yang berarti obesitas. IMT merupakan risiko diabetes mellitus, risiko berarti faktor yang terkait dengan penyebab tetapi risiko ini bukan berarti penyebab secara langsung. Oleh karena itu pengelolaan nutrisi seimbang perlu dilakukan secara dini agar remaja terhindar dari penyakit diabetes mellitus (Widodo \& Retnaningtyas, 2012). Selain itu riwayat keluarga dengan diabetes mellitus menjadi faktor risiko bagi remaja.

Terdapat $62,7 \%$ responden remaja memiliki riwayat keluarga diabetes mellitus. Risiko anggota keluarga menderita diabetes mellitus bila salah satu orang tuanya menderita DM adalah sebesar 15\% (Diabates UK, 2013). Jika kedua orang tua memiliki diabetes mellitus maka risiko untuk menderita diabetes mellitus adalah 75\% (Diabates UK, 2013). Risiko untuk mendapatkan diabetes mellitus dari ibu lebih besar 10-30\% dari pada ayah dengan diabetes mellitus. Hal ini dikarenakan penurunan gen sewaktu dalam kandungan lebih besar dari ibu. Jika saudara kandung menderita diabetes mellitus maka risiko untuk menderita diabetes mellitus adalah $10 \%$ dan $90 \%$ jika yang menderita adalah saudara kembar identik (Diabetes UK, 2013).

Pengetahuan adalah salah satu proses yang diperlukan untuk mengadopsi perilaku yakni kesadaran dimana seseorang telah menyadari dalam arti mengerti stimulus terlebih dahulu. Pengetahuan pada responden remaja di Kota Bekasi dapat di indikasikan sebagai modal utama untuk pencegahan diabetes. Tingkat pengetahuan dapat mempengaruhi sikap dan tindakan seseorang (Achmadi, 2013). Tindakan responden aktivitas fisik yang baik juga dapat dipengaruhi karena individu tersebut mempunyai bekal pengetahuan yang baik pula (Moon, 2017). Selain itu kesadaran masyarakat tentang diabetes mellitus dipengaruhi oleh pengetahuan. Hal ini karena pengetahuan adalah hal mendasar untuk menyadarkan masyarakat supaya berperilaku sehat. Sehingga deteksi dini dari gejala yang ditimbulkan dapat diketahui (Silalahi, 2019).

Selain pengetahuan prediktor faktor preventif diabetes mellitus adalah pola makan dan pola olahraga remaja. Faktor risiko diabetes mellitus memiliki hubungan dengan pola makan, hal ini berkaitan dengan kadar insulin dari asupan 
nutrisi dan pola konsumsi makanan pada remaja. Hal ini sejalan dengan penelitian Spruijit et.al (2018) yang menyatakan bahwa asupan makanan akan mempengaruhi sistem tubuh dan produksi gula darah dalam tubuh. Diperkuat oleh penelitian Marine (2015) yang menyebutkan bahwa sebagian besar remaja dengan orang tua diabetes mellitus berada pada status gizi sangat gemuk. Pada remaja perlu pengurangan frekuensi konsumsi makanan dengan indeks glikemi tinggi dan peningkatan konsumsi buah dan sayur serta aktivitas fisik, terutama pada remaja dengan orang tua diabetes mellitus.

Konsumsi gula memiliki hubungan yang signifikan dengan kejadian diabetes mellitus, apalagi anak-anak hingga remaja memiliki proses metabolik yang berbeda dengan usia dewasa. Sehingga remaja harus memiliki pengetahuan yang cukup tentang bagaimana terjadinya diabetes mellitus yang berhubungan dengan faktor risiko serta nutrisi yang dikonsumsi Malik et.al, (2010). Sedangkan pola olahraga dapat mempengaruhi proses produksi insulin pada tubuh sehingga tidak terjadi penumpukan gula darah dalam tubuh. Pola olahraga atau aktifitas fisik minimal dapat dilakukan selama 30 menit dalam sehari atau 150 menit dalam satu minggu. Hal ini didukung oleh penelitian Padilha De Lima et al., (2019) yang menyatakan bahwa terdapat hubungan antara usia dengan aktifitas fisik terhadap kejadian diabetes mellitus. Selain itu, Sudaryanto et.al (2014) dalam penelitiannya menambahkan bahwa kebiasaan olahraga yang kurang memiliki kemungkinan lima kali terjadi diabetes daripada yang cukup olahraga. Pada penderita diabetes pola olahraga sebelum sarapan pagi sangat berpengaruh terhadap penurunan kadar gula darah (Zheng et al., 2020).

\section{SIMPULAN}

Berdasarkan hasil analisis peelitian yang dilakukan dapat simpulkan bahwa terdapat hubungan antara faktor risiko dengan prediktor preventif diabetes mellitus pada remaja. Selain itu, perlu adanya edukasi kepada remaja sebagai tindakan pencegahan diabetes mellitus. Jumlah responden yang hanya 162 tentunya masih kurang menggambarkan kondisi keseluruhan di Kota Bekasi. Maka dari itu perlu adanya penambahan responden dan penelitian lanjutan tentang epidemiologi diabetes mellitus pada usia remaja.

\section{DAFTAR PUSTAKA}

Achmadi, U. F. (2013). Kesehatan masyarakat teori dan aplikasi. Jakarta: Rajawali Pers.

Badan Pusat Statistik. (2016). Potret awal tujuan pembangunan berkelanjutan: Sustainable Development Goals (SDGs) di Indonesia. Jakarta.

Diabetes UK. (2013). Diabetes in the UK: key statistics on diabates. Retrived from www.diabetes.org.uk.

Gaidhane, S., Mittal, W., Khatib, N., Zahiruddin, Q. S., Muntode, P. A., \& Gaidhane, A. (2017). Risk factor of type 2 diabetes mellitus among adolescents from rural area of India. 600-604. https://doi.org/10.4103/22494863.222025 .

Irawan, Dedi. 2010. Prevalensi dan faktor risiko kejadian diabetes mellitus tipe 2 
di daerah urban Indonesia (Analisa Data Sekunder Riskesdas 2007). Thesis Universitas Indonesia.

Kementerian Kesehatan RI. (2017). Data dan informasi: profil kesehatan Indonesia Tahun 2016. Jakarta.

Kementrian Kesehatan Republik Indonesia. (2018). Riset kesehatan dasar (Riskesdas 2018). Diakses melalui www.depkes.go.id/resources/download/ Riskesdas2018.pdf.

Kozier, Erb, Berman, \& Snyder. (2011). Buku ajar fundamental keperawatan : konsep, proses \& praktik (7 ed., Vol. I). Jakarta: EGC.

K. Van Proeyen, K. Szlufcik, H. Nielens et al., (2010). Training in the fasted state improves glucose tolerance during fat-rich diet, The Journal of Physiology, 588 (21): 4289-4302.

Padilha De Lima, A., Bertoldo Benedetti, T. R., De Oliveira, L. Z., Bavaresco, S. S., \& Rech, C. R. (2019). Physical activity is associated with knowledge and attitudes to diabetes type 2 in elderly, Journal of Physical Education (Maringa), 30(1): 1-10. https://doi.org/10.4025/jphyseduc.v30i1.3017.

Malik VS, Popkin BM, Bray GA, Després J-P, Hu FB. (2010). Sugar-sweetened beverages, obesity, type 2 diabetes mellitus, and car-diovascular disease risk, Circulation, 121: 1356-1364.

Moon, R. B. (2017). Pengetahuan, sikap, dan tindakan terhadap pola hidup terkait faktor risiko diabetes mellitus tipe 2 pada remaja di Kecamatan Mantrijeron Yogyakarta. Skripsi. Yogyakarta: Fakultas Farmasi Universitas Sanata Dharma.

Amiri, E. Al, Abdullatif, M., Abdulle, A., Bitar, N. Al, Afandi, E. Z., \& Parish, M. (2015). The prevalence, risk factors, and skrining measure for prediabetes and diabetes among Emirati overweight/obese children and adolescents. BMC Public Health, 1-9. https://doi.org/10.1186/s12889-015-2649-6.

Dyah Widodo, Ekowati Retnaningtyas, I. F. (2012). Faktor risiko timbulnya diabetes mellitus pada remaja SMU, Jurnal Ners, 7(1): 37-46.

Gaidhane, S., Mittal, W., Khatib, N., Zahiruddin, Q. S., Muntode, P. A., \& Gaidhane, A. (2017). Risk factor of type 2 diabetes mellitus among adolescents from rural area of India. 600-604. https://doi.org/10.4103/22494863.222025.

Kemenkes RI. (2018). Hari diabetes sedunia tahun 2018. Pusat Data Dan Informasi Kementrian Kesehatan RI, 1-8.

Lee, S., Foote, J., Wittrock, Z., Xu, S., Niu, L., \& French, D. C. (2017). Adolescents' perception of peer groups: psychological, behavioral, and relational determinants, Social Science Research, 65: 181-194. https://doi.org/10.1016/j.ssresearch.2016.12.005.

Marine, D. (2015). Perbedaan tingkat pengetahuan, pola konsumsi dan status gizi remaja dengan riwayat orang tua diabetes mellitus (DM) dan tidak riwayat DM, Media Gizi Indonesia, 10(2): 179-183.

Qifti, F., Malini, H., \& Yetti, H. (2020). Karakteristik remaja SMA dengan faktor risiko diabetes mellitus di Kota Padang, Jurnal Ilmiah Universitas Batanghari Jambi, 20(2), 560. https://doi.org/10.33087/jiubj.v20i2.950

Silalahi, L. (2019). Hubungan pengetahuan dan tindakan pencegahan diabetes 
mellitus tipe 2. Jurnal PROMKES, 7(2), 223. https://doi.org/10.20473/jpk.v7.i2.2019.223-232.

Sudaryanto, A., Setiyadi, Alis, N., \& Frankilawati, Ayu, D. (2014). Hubungan antara pola makan, genetik dan kebiasaan kerja Puskesmas Nusukan, Banjasari. Prosiding SNST, (3), 19-24.

Wahyuni, S., \& Alkaff, R. N. (2013). Diabetes mellitus pada perempuan usia reproduksi di Indonesia. Jurnal Kesehatan Reproduksi, 3(1): 46-51.

Zheng, X., Qi, Y., Bi, L., Shi, W., Zhang, Y., Zhao, D., Li, Q. (2020). Effects of exercise on blood glucose and glycemic variability in type 2 diabetic patients with dawn phenomenon. BioMed Research International. https://doi.org/10.1155/2020/6408724

Spruijit-metz, D., Reilly, G. A. O., Cook, L., Page, K. A., \& Quinn, C. (2014). Behavioral Contributions to the Pathogenesis of Type 2 Diabetes. https://doi.org/10.1007/s11892-014-0475-3 